\title{
O CAMINHO DOS PROFESSORES NA EDUCAÇÃO PROFISSIONAL: percepções sobre o sentido do trabalho e do trabalho docente ${ }^{i}$
}

\author{
J. K. C Morais, M. G. M Santos* e P. A. F. Brandão \\ Programa de Pós Graduação em Educação Profissional (PPGEP) \\ Instituto Federal de Educação, Ciência e Tecnologia do Rio Grande de Norte (IFRN) \\ kaio-ca-valcante@hotmail.com,grs_apodi@hotmail.com, pollyanna.araujo@ifrn.edu.br
}

Artigo submetido em abril/2017 e aceito em maio/2017

DOI: $10.15628 /$ rbept.2017.5717

\section{RESUMO}

O presente artigo é resultado de uma pesquisa realizada durante a disciplina de Formação Docente para Educação Profissional (EP) do Programa de PósGraduação em Educação Profissional do Instituto Federal do Rio Grande do Norte (PPGEP/IFRN). A pesquisa de caráter qualitativo teve por objetivo analisar os conceitos de trabalho e trabalho docente de professores que atuam na EP. Foram realizadas entrevistas com professores da área de formação técnica de duas instituições de ensino profissionalizante do município de Natal/RN. Para sistematizar a coleta de dados, utilizamos o instrumento de Análise de Conteúdos de Bardin (2011). Após a análise dos dados, identificamos que os professores concebiam o trabalho docente de forma distinta de outros tipos de trabalho, todavia, não conseguiram sinalizar quais saberes eram específicos da prática docente. Para a realização da referida pesquisa, entre os autores que fundamentaram - referencial teórico, podemos destacar: Antunes (2013), Ciavatta (2012), Marx (1980), Moura (2013), Ramos (2014) e Saviani (2003).

PALAVRAS-CHAVE: Educação profissional, formação docente, trabalho e trabalho docente.

\section{THE WAY OF TEACHERS IN VOCATIONAL EDUCATION: perceptions about the meaning of work and teaching work}

\section{ABSTRACT}

This article is the result of a survey conducted during the course of Teacher Training for Professional Education (EP) of the Graduate Program in Professional Education of the Federal Institute of Rio Grande do Norte (PPGEP / IFRN). The qualitative study aimed to analyze the concepts of work and teaching work of teachers who work in the EP. Interviews were conducted with technical training area teachers from two training institutions in the city of Natal / RN. To systematize data collection, use the instrument of Bardin Content
\end{abstract}

Analysis (2011). After analyzing the data, we found that teachers conceive the teaching work differently from other types of work, however, failed to signal which were specific knowledge of teaching practice. For the realization of this research, among the authors that supported the theoretical framework, we can highlight: Antunes (2013), Ciavatta (2012), Marx (1980), Moura (2013), Ramos (2014) and Saviani (2003).

KEYWORDS: vocational education, teacher training, work and teaching work. 


\section{APRESENTAÇÃO}

O presente estudo decorre de uma atividade avaliativa da disciplina Formação docente para a Educação Profissional, do mestrado acadêmico em Educação Profissional do Instituto Federal de Educação, Ciência e Tecnologia do Rio Grande do Norte. Nos foi proposto - para toda turma de mestrandos - investigar a formação inicial e continuada de professores que atuam em duas (2) instituições de ensino que ofertam essa modalidade de ensino.

Os nomes das instituições de ensino profissionalizante, locus da pesquisa, serão preservados em sigilo. Com isso, optamos por criar códigos para identificação das referidas instituições:

Quadro 1: Códigos representativos das instituições de ensino

\begin{tabular}{|l|l|}
\hline Instituição de Ensino 1 & IE1 \\
\hline Instituição de Ensino 2 & IE2 \\
\hline
\end{tabular}

Fonte: autoria própria

Ambas as instituições estão localizadas na Região Metropolitana de Natal/RN. Nessas escolas técnicas, os mestrandos entrevistaram professores com formação para a área específica (PFE) e Professor com Formação Geral (PFG), sendo o foco deste artigo, os professores das áreas específicas dos cursos técnicos no qual estavam habilitados a lecionar. Esses docentes atuavam em três (3) cursos distintos:

Quadro 2: Códigos representativos dos cursos e dos professores

\begin{tabular}{|l|l|}
\hline Curso de Enfermagem (CE) & $\begin{array}{l}\text { Professor do Curso de Enfermagem com Formação Específica } \\
\text { (PFCEE) }\end{array}$ \\
\hline Curso de Radiologia (CR) & Professor do Curso de Radiologia com Formação Específica (PFCRE) \\
\hline Análises Clínicas (AC) & $\begin{array}{l}\text { Professor do Curso de Análises Clínicas com Formação Específica } \\
\text { (PFACE) }\end{array}$ \\
\hline
\end{tabular}

Fonte: autoria própria

Utilizamos a entrevista semiestruturada como instrumento de levantamento de dados, pois, conforme afirma Manzini (1990), a entrevista pode fazer emergir informações de forma mais livre e respostas não condicionadas a uma padronização de alternativas.

Moreira e Caleffe (2008) enumeram alguns critérios que devem ser obedecidos ao escolher a entrevista como instrumento metodológico. Segundo eles, a entrevista é muito usada em quase todas as disciplinas das ciências sociais e na pesquisa educacional como uma técnica chave no levantamento dos dados, ainda que apresente uma considerável diversidade de formas e estilos vinculados à natureza das perguntas, ao grau de controle exercido pelo entrevistador sobre o entrevistado, ao número de pessoas envolvidas e à posição geral da entrevista no delineamento da pesquisa. Por fim, os autores afirmam que a entrevista, dentro do princípio das pesquisas de caráter qualitativo, pode ser considerada como uma conversa com um propósito. 
Concordando com isso pensamos, para o nosso trabalho, em desenvolver uma entrevista em que os sujeitos também apresentassem essa sensação de diálogo, de uma conversa aberta. Por outro lado, em vista do rigor científico, sentimos também a necessidade de estabelecer um roteiro norteador das questões levantadas, considerando-se o objeto de estudo em evidência. Disso derivou-se o uso da entrevista semiestruturada.

Dalbério e Dalbério (2009) alertam que, na entrevista, a construção e a aplicação do instrumento devem estar em consonância direta com o objeto de estudo, com a questão norteadora e com a consistência teórica e prática na preparação do percurso da pesquisa. Foi este sentido, portanto, que buscamos seguir.

Em meio a isto, também prezamos pelo respeito aos entrevistados, uma vez que garantimos sigilo sobre as suas identidades. Dalbério e Dalbério (2009, p. 216) comentam que "na entrevista, o respeito pelo entrevistado é uma questão ética fundamental. Por isso, o sigilo, o anonimato, o local e o horário marcado garantem compromisso com o sujeito entrevistado". Sendo assim, optamos por manter em sigilo as identidades dos sujeitos, bem como a vinculação do mesmo com as instituições participantes da pesquisa.

A entrevista semiestruturada apresentava um número específico de questões, em que se discutiam três (3) categorias específicas: percurso formativo; percepção de trabalho e trabalho docente e relação teoria e prática na atuação docente.

Sendo assim, para a produção específica do presente artigo, centramos nosso olhar na categoria do trabalho e trabalho docente. Logo, utilizamos as falas dos professores da área específica que atuam nos três (3) cursos, contabilizando seis (6) professores entrevistados, dois (2) de cada curso, todos, da área específica do curso.

Tendo realizado o levantamento dos discursos dos sujeitos, a partir da entrevista semiestruturada gravada e, posteriormente, transcrita, partimos para as análises dos dados, tomando como norte a análise do conteúdo proposta por Bardin (2011). De acordo com a autora (apud ALBINO, 2014), a análise do conteúdo constitui-se em um conjunto de técnicas de análise das comunicações que visa obter, por procedimentos sistemáticos e objetivos aplicados sobre o conteúdo das mensagens, indicadores que permitam a inferência de conhecimentos relativos a essas mensagens.

De acordo com Albino (2014), podemos afirmar que a escolha da análise de conteúdo como meio de interpretação dos dados de uma pesquisa não se vincula unicamente a uma opção do pesquisador, mas a todo o procedimento adotado, ao tipo de material existente para a análise, aos objetivos a que se propõe a investigação e, principalmente, ao objeto de estudo enfatizado. Acreditamos que a técnica de análise escolhida coaduna com os objetivos do trabalho, bem como o percurso metodológico e o objeto de estudo em questão.

Pensado no objeto de estudo, no instrumento de pesquisa e na técnica de análise, compreendemos que precisaríamos de um método para guiar nossa análise da categoria, por isso, optamos pelo método histórico-dialético, por entender que esse aborda a questão do trabalho e do trabalho docente a partir de uma visão holística e de totalidade.

Esclarecido o objetivo da pesquisa como um todo, deixaremos claro que o objetivo do presente artigo é analisar as percepções dos professores que atuam na educação profissional da rede privada de ensino de $\mathrm{Natal} / \mathrm{RN}$ a respeito do trabalho e do trabalho docente.

O estudo encontra-se organizado a partir do tópico de apresentação e mais quatro (4) outros tópicos, a saber: a educação profissional e os sentidos do trabalho; o trabalho docente na educação profissional; percepções dos docentes sobre o trabalho e o trabalho docente e considerações finais. 


\section{A EDUCAÇÃO PROFISSIONAL E OS SENTIDOS DO TRABALHO}

A educação profissional é uma modalidade de ensino que tem no bojo da sua história, a formação para o trabalho. Pode parecer curioso pensar em uma modalidade de ensino que prepare para a formação profissional do indivíduo, uma vez que o trabalho transcende a existência dessa modalidade, o que nos faz reforçar que o trabalho sempre fez parte da vida humana e que esse conhecimento era repassado de geração em geração entre as comunidades. Não havia necessidade de uma formação específica para o trabalho, visto que suas atividades eram consideradas simples e desempenhadas pelos escravos, indígenas e grupo de classe econômica baixa. A educação - formalizada - era destinada à burguesia e tinha como objetivo preparar o homem para as profissões consideradas elitizadas e de grande prestígio na sociedade.

Em períodos de crise do capital nos Estados Unidos com a alta taxa de inflação, nas décadas de 1970 e 1980, a economia capitalista precisou se reinventar através de novas estratégias econômicas para aumentar a lucratividade e a produtividade dos negócios. Logo, a educação profissional veio a se desenvolver a partir da necessidade de qualificar mão de obra para atender ao desenvolvimento do capital. No Brasil, durante o século XX, com o avanço industrial, houve a necessidade de implementar estratégias para potencializar a produção das fábricas.

Essa contextualização se faz necessária para compreendermos a função dessa modalidade de ensino em nosso país e os sentidos do trabalho que estavam relacionados à Educação Profissional (EP). Portanto, não é possível discutir educação profissional sem nos atentarmos à que tipo de trabalhador se propõe formar para sociedade.

Marx (1983) afirma que o trabalho é uma atividade intrínseca ao ser humano e necessária à sua sobrevivência. $\mathrm{O}$ autor define o conceito de trabalho como fruto da relação do homem com a natureza à medida que se apropria dela e a transforma para atender as necessidades da vida humana.

\footnotetext{
O trabalho é um processo entre o homem e a natureza, um processo em que o homem, por sua própria ação, media, regula e controla seu metabolismo com a Natureza. Ele mesmo se defronta com a matéria natural com uma força natural. Ele põe em movimento as forças naturais pertencentes à sua corporeidade, braços, pernas, cabeça, e mãos, a fim de se apropriar da matéria natural numa forma útil à própria vida. Ao atuar, por meio desse movimento, sobre a natureza externa a ele e ao modificá-la, ele modifica, ao mesmo tempo, sua própria natureza (MARX, 1983, p.149).
}

O autor apresenta o conceito de trabalho numa perspectiva ontológica. Sobre o trabalho ontológico, Saviani (2007, p. 154) afirma que

Diríamos, pois, que no ponto de partida a relação entre trabalho e educação é uma relação de identidade. Os homens aprendiam a produzir sua existência no próprio ato de produzi-la. Eles aprendiam a trabalhar trabalhando. Lidando com a natureza, 
relacionando-se uns com os outros, os homens educavam-se e educavam as novas gerações.

A definição de Saviani (2007) reflete o trabalho humano em um período histórico, o qual não existia divisão de classes. As comunidades primitivas se apropriavam coletivamente dos meios de produção para produzir a sua existência. A educação e o trabalho estavam estritamente ligados, a educação para o trabalho significava o mesmo que educação para a vida.

Saviani (2007) nos diz que a separação histórica entre trabalho e educação emergiu a partir do desenvolvimento da produção.

\begin{abstract}
O desenvolvimento da produção conduziu à divisão do trabalho e, daí, à apropriação privada da terra, provocando a ruptura da unidade vigente nas comunidades primitivas. A apropriação privada da terra, então o principal meio de produção, gerou a divisão dos homens em classes. Configuram-se, em consequência, duas classes sociais fundamentais: a classe dos proprietários e a dos não-proprietários (SAVIANI, 2007, P.155).
\end{abstract}

Se o conceito de trabalho ontológico tem como princípio a educação para vida, logo a divisão do trabalho também irá produzir a divisão da educação. Isto é, a educação dos homens se constituirá a partir da divisão de classes sociais. É por meio desse raciocínio que se desenvolveu a dualidade entre educação e trabalho:

\begin{abstract}
A partir do escravismo antigo passaremos a ter duas modalidades distintas e separadas de educação: uma para a classe proprietária, identificada como a educação dos homens livres, e outra para a classe não-proprietária, identificada como a educação dos escravos e serviçais (SAVIANI, 2007, P. 155).
\end{abstract}

Nesse sentido, a educação para as classes sociais se constituiu em dois segmentos, um voltado para o desenvolvimento intelectual, físico e artístico, e, outro para apropriação dos processos de trabalho.

Ao analisarmos o contexto histórico da dualidade entre trabalho e educação, identificamos que essa ruptura foi decorrente do desenvolvimento dos meios de produção. 0 trabalho perde o seu sentido ontológico e assume um caráter de alienação. Por meio do trabalho alienado, a classe burguesa explora o trabalhador que vende a sua força de trabalho. $O$ capital vai se desenvolver a partir da produção em massa e, consequentemente, do aumento dos lucros.

No contexto da educação profissional, ao investir no nível de conhecimento do trabalhador era possível gerar mais lucratividade para as empresas. Shcultz (1973) desenvolveu a Teoria do Capital Humano fundado no princípio de que algumas empresas se tornavam mais competitivas do que outras, mesmo em condições aparentemente iguais. Para ele, o que se destacava nas empresas mais competitivas era o nível de conhecimento dos trabalhadores. 0 conhecimento humano é uma forma de capital e, consequentemente, capaz de gerar lucro. Para Schultz (1973): 


\begin{abstract}
O investimento nos assuntos escolares, no treinamento realizado no trabalho, na saúde, na informação de emprego e na imigração possibilitam a produtividade de valor das capacidades adquiridas do homem, em levarem ao desenvolvimento de medidas de mudanças na qualidade do trabalho que podem ser quantificadas (SCHULTZ 1973, p. 26).
\end{abstract}

O autor explica que o trabalhador deveria ser empreendedor do seu próprio conhecimento, tornando-se uma força de trabalho qualificada.

Os trabalhadores transformaram-se em capitalistas [...]. Esse conhecimento e essa capacidade são em grande parte o produto do investimento e, combinados com outros investimentos humanos, são responsáveis predominantemente pela superioridade produtiva dos países tecnicamente avançados. Omiti-los, ao estudar-se o crescimento econômico, é o mesmo que explicar a ideologia soviética sem a figura de Marx (SCHULTZ, 1973, p. 35, grifo nosso).

Dessa forma, o capital impõe ao trabalhador a responsabilidade de buscar a aquisição do conhecimento para se manter no mercado de trabalho. Em tempos de crise, o trabalhador é responsável por ter um currículo em condições de empregabilidade, desenvolvendo competências diversas para se adaptar à flexibilidade das necessidades de força de trabalho para o capital.

Sendo assim, a educação que deveria ser voltada para a formação integral do homem em todas as suas necessidades humanas, passa a ter o papel de atender ao capital.

Para Moura (2013), a educação para o trabalho é submetida ao neoliberalismo

A educação é considerada como instrumento voltado para a formação de competências destinadas à inserção dos indivíduos no mercado de trabalho, já que os trabalhadores são mão de obra a ser comercializada nesse grande mercado. Em outras palavras, o valor da educação está em sua instrumentalidade (formar para o mercado). Já o trabalho é confundido com emprego nas suas mais diversas formas: fixo (para a minoria), temporário, terceirizado, quarteirizado etc., em grande maioria precarizados. Dessa forma, o conceito de trabalho em seu sentido ontológico é negligenciado, assumindo-se apenas o seu sentido histórico - emprego, sob hegemonia do modo de produção capitalista. Entretanto, como o capitalismo sob a hegemonia neoliberal é incompatível com a possibilidade de emprego para todos, forjou-se o conceito de empregabilidade como sendo a capacidade de o indivíduo tornar-se empregável (MOURA, 2013, p. 127, grifo do autor). 
Dessa forma, percebemos que o projeto pedagógico da educação profissional não permite ao trabalhador apropriar-se do conhecimento de modo a melhorar a sua vida e transformar a sua realidade, visto que a sua formação é limitada às competências voltadas para as necessidades do mercado de trabalho. Sendo assim, os seus conhecimentos serão limitados, o que não proporcionará uma visão mais crítica do seu papel na sociedade.

O filho do trabalhador sempre será mão de obra, força de trabalho explorada e o filho do burguês será o que ocupará as profissões mais qualificadas e elitizadas. Na sociedade capitalista, - Estado se omite da sua função social de garantir educação de qualidade para todos e transmite para o capital esse poder. Aos trabalhadores cabe o investimento pessoal na aquisição do conhecimento, enquanto condição de empregabilidade imposta ao trabalhador pelo capital.

O sistema capitalista tornou a classe trabalhadora reciclável e descartável. E o que resta aos trabalhadores? Pagar por uma educação profissional para se manter no mercado de trabalho, visto que o Estado passou também a privatizar a educação profissional. Para Alves (2006), os princípios de eficiência e produtividade se concretizam por meio das escolas profissionalizantes

O discurso da produtividade, do desemprego e da competência ligada à eficiência econômica penetra, cada vez mais, nas escolas, universidades, meios de comunicação e sindicatos. Antes de ser uma política de gestão estatal, o neoliberalismo parece ser uma cultura (e uma psicologia) do capital e de seu sociometabolismo (ALVES, 2006, p. 23).

O discurso neoliberal é absorvido nas práticas pedagógicas das escolas de educação profissional por meio dos princípios da Pedagogia das Competências:

Do ponto de vista do trabalhador, a educação assume feições perversas, uma vez que, para os que vivem do trabalho, a aprendizagem de conhecimentos e habilidades, instrumentais e cognitivas, são imediatamente vinculadas ao exercício de atividades produtivas. É condição não só de existência, mas também da própria permanência no sistema de ensino, na maioria das vezes viabilizada pelo ingresso no mercado de trabalho (KUENZER, 2009, p. 41).

Neste artigo, defendemos uma proposta de educação profissional pautada no trabalho ontológico, contrária à proposta pedagógica da pedagogia das competências. Trataremos a expressão "formação integral" de forma sinônima à "educação politécnica". Moura, Lima Filho e Silva (2012) explicam que a concepção de politecnia está relacionada à concepção de formação humana integral na tradição Marxiana. Sobre Karl Marx, os autores afirmam que "ao tratar de educação intelectual, física e tecnológica, Marx está claramente sinalizando para formação integral do ser humano, ou seja, uma formação que abrange todas as dimensões da vida e, portanto, é onilateral" (MOURA, SILVA FILHO E SILVA, 2012, p.5).

Sobre Politecnia, Saviani (2003, p.137) afirma que: 


\begin{abstract}
A noção de politecnia se encaminha na direção da superação da dicotomia entre trabalho manual e trabalho intelectual, entre instrução profissional e instrução geral. A sociedade moderna, que generaliza as exigências do conhecimento sistematizado, é marcada por uma contradição: como se trata de uma sociedade alicerçada na propriedade privada dos meios de produção, a maximização dos recursos produtivos do homem é acionada em benefício da parcela que detém a propriedade dos meios de produção, em detrimento da grande maioria, os trabalhadores, que possuem apenas sua força de trabalho. Na sociedade capitalista, a ciência é incorporada ao trabalho produtivo, convertendo-se em potência material. O conhecimento se converte em força produtiva e, portanto, em meio de produção. Assim, a contradição do capitalismo atravessa também a questão relativa ao conhecimento: se essa sociedade é baseada na propriedade privada dos meios de produção e se a ciência, como conhecimento, é um meio de produção, deveria ser propriedade privada da classe dominante (2003, p.137).
\end{abstract}

Saviani (2003), ao propor a superação da dicotomia entre trabalho manual e trabalho intelectual, e Frigotto (1999), ao discutir o trabalho como princípio educativo pela integração entre educação, trabalho, tecnologia, ciência e cultura, apontam para uma formação politécnica que deve subsidiar a educação profissional no Brasil.

Busca-se a partir dessa formação onilateral às classes trabalhadoras, propiciar uma leitura mais crítica sobre o papel que ocupam na sociedade. Para além da instrumentalização, a escola emancipatória deverá ser o local de troca de experiências e de diálogo para o fomento da superação das desigualdades sociais.

\title{
3. O TRABALHO DOCENTE NA EDUCAÇÃO PROFISSIONAL
}

Ao nos determos sobre a discussão dos sentidos do trabalho, devemos também nos atentar a questão da natureza do trabalho docente na educação profissional. O professor que atua na educação profissional assume características bem singulares quanto a sua área de atuação.

Os cursos profissionalizantes possuem eixos tecnológicos específicos do curso profissionalizantes compostos pelas disciplinas da área técnica de um determinado curso e eixos de áreas comuns constituídas pelas disciplinas de formação geral. Nesses 2 (dois) grupos podemos nos deparar com perfis de professores distintos.

Os da área técnica, em sua maioria, são professores com formação na área profissional do curso que atuam, por exemplo, cursos de engenharia e saúde. Não possuem formação em licenciatura. Já o da formação geral, normalmente, participam os professores das disciplinas propedêuticas com formação em alguma licenciatura que ministram aulas em cursos profissionalizantes distintos.

Mesmo o grupo de professores que possuem licenciatura, não possuem uma formação específica para a educação profissional, uma vez que essa modalidade, em sua maioria, não se encontra nas matrizes curriculares dos cursos de graduação nas instituições de ensino superior.

Logo, os cursos de formação continuada constituem espaços valiosos de capacitação para esses professores. E quando não são propiciados momentos de diálogos para a formação desses docentes, é possível que, no discurso dos professores, esteja intrínseco a reprodução da pedagogia das competências, da formação para o mercado de trabalho e das necessidades do capital. 
Por isso, se faz necessário que esse professor que atua na Educação Profissional tenha as condições necessárias de agir reflexivamente sobre a sua prática de ensino e possibilitar situações de aprendizagem que ajudem aos alunos a perceber o papel que ocupam na sociedade e agir coletivamente para a sua emancipação.

Todavia, esse professor deverá conscientizar-se de que o trabalho docente se distingue de outros tipos de trabalho. O professor da área técnica, deverá desenvolver além das habilidades especificas da sua formação profissional, os saberes necessários à atuação docente.

Compreende-se que esse professor deverá atuar para que o trabalhador além de se apropriar dos conhecimentos necessários ao mundo do trabalho, possa também compreender as desigualdades sociais estabelecidas pelas relações de poder entre o capital e a classe trabalhadora.

Alarcão (2008, p. 06) enfatiza que é necessário o desenvolvimento de uma "atitude de estar na profissão professor como intelectual que criticamente questiona e se questiona", um processo que envolve uma compreensão sistemática para melhor atuar na resolução dos problemas que se fazem presentes no cotidiano da escola.

Demo (2007) vai contribuir para essa discussão com a proposta de educação pela pesquisa. A ideia de professor pesquisador, para ele, envolve qualidade formal e política. Formal no sentido de aprendizagem sistemática do conhecimento metodológico, que envolve o desenvolvimento de uma pesquisa, e como atitude política que requer a consciência social nos procedimentos centrados no como ensinar.

Esse processo se constrói nas dimensões individuais e sociais, cabendo aos sujeitos buscarem sua formação pessoal, mas também as instituições abrirem espaços de discussão, pois não devem perder de vista a reflexão sobre o que é educar e qual sua finalidade, fazendo-se na discussão coletiva, no diálogo e na dialogicidade (FREIRE, 1983).

\section{PERCEPÇÕES DOS DOCENTES SOBRE O TRABALHO E SOBRE O TRABALHO DOCENTE}

Como foi visto na metodologia, utilizamos a entrevista semiestruturada como instrumento de pesquisa. Para análise dos dados, recorremos à análise de conteúdo de Bardin (2011). Posto isso, chegamos a um número quantitativo de temas, uma vez que estes encontraram-se mais presentes nas falas dos sujeitos. No Quadro 1, podemos observar os temas.

Quadro 3: demonstrativo dos temas mais recorrentes nas falas dos sujeitos entrevistados

\section{TEMAS RECORRENTES}

\begin{tabular}{|l|l|}
\hline Tema 1 & O trabalho é luta, dádiva, compromisso e ofício \\
\hline Tema 2 & O trabalho tem relação com o mercado de trabalho \\
\hline Tema 3 & A natureza do trabalho docente é uma extensão do trabalho técnico. \\
\hline Tema 4 & $\begin{array}{l}\text { O trabalho docente é caracterizado de desafios e dilemas que ultrapassam a } \\
\text { atuação na área técnica. }\end{array}$ \\
\hline Tema 5 & O papel da Educação Profissional é formar para o mercado de trabalho \\
\hline
\end{tabular}

Fonte: autoria própria

Como resultado das análises das transcrições das entrevistas a partir da técnica da análise do conteúdo, cinco (5) temas surgiram. Alguns deles apresentaram similaridades, o que nos 
conduziu a formar categorias, coadunando também com os princípios da técnica de análise do conteúdo.

A primeira categoria foi composta pelos temas um (1) e dois (2), por isso, a denominamos pelo seguinte título: $O$ trabalho é ofício, luta e compromisso: traços de uma visão histórica da natureza do trabalho e do trabalho docente.

A segunda categoria, por sua vez, centra seu olhar em problematizar a visão dos entrevistados com relação à percepção deles sobre o trabalho docente. Estão incluídos nessa categoria os temas três (3) e quatro (4). Por esse motivo, a classificamos como: ser professor na educação profissional é uma extensão do fazer técnico, mas que apresenta desafios inerentes ao trabalho docente.

Um dos temas não apresentou similaridade para ser enquadrado nas categorias citadas nos parágrafos anteriores. Apesar disso, discorreremos sobre o tema pelo fato de estar presente na fala dos entrevistados com recorrência.

\subsection{O TRABALHO É OFÍCIO, LUTA E COMPROMISSO: TRAÇOS DE UMA VISÃO HISTÓRICA DA NATUREZA DO TRABALHO E DO TRABALHO DOCENTE}

Pretendemos desenvolver a análise tomando como embasamento teórico o método histórico-dialético. Portanto, nosso olhar sobre os dados é embasado teoricamente pelos pressupostos da visão socialista e marxista do trabalho.

Nessa abordagem, o trabalho é visto como primeira e principal mediação entre o homem e a natureza. É a partir do trabalho que o homem constrói e reconstrói a natureza, bem como a si mesmo. O homem aprende a trabalhar, ensina essa aprendizagem e transfere para outras gerações. Dessa forma, o homem produz conhecimento, tecnologia e cultura a partir do trabalho.

Marx (1980, p.59) assegura nossa abordagem ao comentar que "o trabalho, por isso, é uma condição de existência do homem, independentemente de todas as formas de sociedade, eterna necessidade natural de mediação do metabolismo entre homem e natureza e, portanto, vida humana".

No decorrer da história, o trabalho vem assumindo várias formas, como: o trabalho escravo, o trabalho autônomo dos artesãos pré-revolução industrial, dentre outros. A partir da revolução industrial, sob a hegemoniaii do modo de produção capitalista, o trabalho assume majoritariamente a forma de emprego, na qual o trabalhador vende a sua força de trabalho iii para o detentor do capital no mercado de trabalho (MOURA, 2013).

A partir da sociedade capitalista, a conjuntura e a apropriação do trabalho pelos donos do meio de produção foi delimitando um percurso que se encontra ainda muito presente em nossa atual sociedade: o trabalho na forma de emprego. O que era uma finalidade central do ser humano, converte-se em meio de subsistência e de interesses. A força de trabalho torna-se uma mercadoriaiv , cuja finalidade é criar novas mercadorias e valorizar o capital. Transforma-se em meio e não em primeira necessidade de realização humana (HARVEY, 2013; ANTUNES, 2013).

Sendo assim, localizamos, na literatura especializada, duas (2) abordagens com relação ao conceito de trabalho. $O$ trabalho visto a partir de uma visão histórica e o trabalho em seu sentido ontológico.

Como vimos anteriormente, as falas dos sujeitos entrevistados se aproximam de uma abordagem sobre o trabalho a partir de uma visão histórica. Não foi percebido na análise dos 
dados uma repetição dos discursos que se aproximasse de uma visão sobre o trabalho a partir de uma percepção ontológica.

Isso pode ser observado nos discursos dos sujeitos a seguir

Assim é responsabilidade, né? Respeito, pontualidade (PFCEE1).

Trabalho... [PENSANDO]. Assim, o trabalho eu acho que é a força, é ... como eu posso explicar, é a mão-de-obra né? A mão-de-obra que ela é aplicada a uma determinada função. Acredito que seja isso (PFCEE2).

É um processo de dedicação, aonde eu consigo ter a oportunidade de compartilhar o que eu aprendi, tanto dentro da teoria e, principalmente, dentro da prática, que é o foco principal para um curso técnico. É a parte prática (PFACE2).

Esforço. Primeira palavra que vem, se diz trabalho eu penso em esforço. Quando se diz assim "ah é um emprego", emprego é uma função que você tem que desenvolver com responsabilidade, quando se diz trabalho soa cansativo, nossa, então é cansativo, eu vou ter que me dedicar, o emprego soa como satisfação, o trabalho eu preciso me esforçar para alcançar (PFCRE2).

(...) que esse trabalho venha então posteriormente a nos trazer um retorno intelectual assim como um retorno financeiro (PFCACE2).

Como pode ser observado nas falas, nenhum deles mostrou elementos que aproximasse o discurso a uma visão do trabalho em seu sentido ontológico. As percepções estiveram centradas em abordagens que se assemelham ao senso comum, ou seja, a uma visão histórica do trabalho.

Isso ficou ainda mais evidente quando em alguns discursos os professores entrevistados ligavam o trabalho à necessidade de preparo de mão-de-obra para o mercado de trabalho, conforme pode ser lido no trecho a seguir

(...) a formação profissional vai abrir portas principalmente pro mercado de trabalho e pra todos esses alunos, e abrindo portas pra o mercado de trabalho, isso vai refletir numa qualidade de vida melhor, uma vez que esses indivíduos estando inseridos no mercado de trabalho, eles podem ter um poder... digamos assim, um poder econômico maior e esse poder econômico maior pode vir a refletir a um bem estar digamos assim até psicossocial dessa pessoa melhor, e com isso é é é essa melhor qualidade de vida faz com que [fala confusa] ô... demonstra um papel inovador do ensino e demonstra mais uma vez o quanto o ensino é importante (PFCRE2)

Compreendemos que essa percepção sobre a formação humana e, sobretudo, a formação para o trabalho coaduna com os princípios e fundamentos da educação neoliberal, centrada nas demandas do mercado de trabalho, no qual o estudante funciona como uma máquina, que deve ser adestrada para entender o todo, mas sem o direito de refletir e problematizar sobre seu trabalho e as implicações deste para a sociedade.

Acreditamos que o caminho para reverter esse quadro é investindo em um projeto de educação que se contraponha a este exposto acima. Coadunamos com Ciavatta (2012), Ramos 
(2015) e Moura (2013), na defesa de um projeto de educação que leve em consideração o trabalho, mas não em seu sentido em histórico, mas ontológico.

Defendemos a que a ausência do sentido ontológico do trabalho nos discursos tenha aspecto direto com a formação inicial e até mesmo continuada dos sujeitos. Pressupomos que esse processo formativo não evidenciou, em suas bases, o sentido do trabalho a partir de uma visão ontológica, consequentemente, não corroborou no intento de transcender a visão dos alunos - hoje professores - com relação à visão que tinham sobre o trabalho construída socialmente.

\title{
4.2 SER PROFESSOR NA EDUCAÇÃO PROFISSIONAL: UMA EXTENSÃO DO FAZER TÉCNICO
}

Apesar dos sujeitos entrevistados não apresentarem formação para docência, haja vista que todos são da área específica do curso técnico profissionalizante - lócus de pesquisa -, apresentando formação variada - alguns com curso técnico, outros com curso superior na área do curso em que lecionam -, os questionamos sobre a especificidade do trabalho docente.

Nesse ponto, os professores esclarecem que o trabalho que exercem no contexto escolar é uma extensão de suas práticas em outros contextos de trabalho, como por exemplo, a professora formada em enfermagem que trabalhou em hospitais e também leciona ultimamente.

Eles defendem que o trabalho docente é uma extensão do trabalho anteriormente desenvolvido em outros espaços, mas que apesar disso, o trabalho do professor apresenta especificidades. Isso pode ser observado nos trechos a seguir

\footnotetext{
(...) nós trabalhamos em sala de aula com teoria, mas também fazemos nossas práticas, então sempre trazemos para perto, a relação da teoria prática. Então sei lá a gente entra diretamente com o paciente, com o cliente, aqui é com nosso aluno, porém fazendo coisas, procedimentos como se fosse num hospital (PFCEE1)

(...) o docente precisa antes de tudo conhecer a área. Ééé..., aqui nós temos o curso técnico de enfermagem, onde a maioria do do dos docentes são enfermeiros, então eles conhecem a rotina, aaaah dos dos docentes de análises clínicas vai variar entre farmacêuticos e biólogos, que a maioria das das disciplinas é de cunho biológico, mas conhecer a rotina de um laboratório, conhecer a rotina de um técnico de análises clínicas é fundamental (...) (PFACE2).
}

\begin{abstract}
Existe sim. Eu ainda acho que é dedicação, mas eu penso em dedicação para docência de forma superior pois agora eu não estou mais fazendo o que sei, eu estou ensinando o que sei, quando você executa a prática é uma coisa, mas quando você ensina aquilo que está na prática é diferente, então a dedicação, então, que era simples vai para um nível superior (...) (PFCRE2).
\end{abstract}

Dessa forma, percebemos que os discursos reconhecem a especificidade do trabalho do professor e estabelecem uma relação direta com o seu fazer profissional em outros espaços. Isso nos evidencia que esses profissionais pensam o fazer docente como uma extensão de trabalhos anteriormente desenvolvidos.

Apesar dessa abordagem, não constatamos nos discursos pressupostos pedagógicos do trabalho docente, nem com relação à sua natureza e à sua finalidade. As falas centraram em 
aspectos práticos, cotidiano, evidenciado as fragilidades no que concerne à conceituação e ao conhecimento com relação às especificidades do trabalho docente.

No que tange às especificidades e natureza do trabalho docente, coadunamos com a discussão levantadas pela Basso (1998), em que ela comenta que o trabalho docente deveria estabelecer uma função mediadora entre o aluno e os instrumentos culturais que poderiam ser apropriados, visando ampliar e sistematizar a compreensão da realidade - isso inclui a realidade cruel do próprio modo de produção capitalista -, possibilitando a objetivação do conhecimento historicamente construído pela humanidade.

Logo, a principal finalidade do trabalho do professor é mediar e ressignificar o conhecimento historicamente construído. Isso se faz a partir de interações entre professores e alunos em espaço escolar.

Tardif (2014) concorda com essa ideia, acrescentando que o professor trabalha com sujeitos que são individuais e heterogêneos, têm diferentes histórias, ritmos, interesses necessidades e afetividades. Isso torna as situações de ensino complexas, únicas, imprevisíveis e incabíveis em generalizações ou esquemas pré-definidos de ação.

Dessa forma, o trabalho do professor deveria atender a todas as exigências da contemporaneidade, a formação integral dos alunos, possibilitando-lhes o acesso à cultura geral, ao conhecimento científico, à comunicação e ao raciocínio lógico. Deve também trabalhar com os alunos as diversas dimensões do ser humano para alcançar sua plena formação psicológica, afetiva e emocional (PASCHOALINO, 2015).

Sendo assim, compreendemos que os discursos dos sujeitos entrevistados ficaram no plano prático e do senso comum, uma vez que não explicitaram as bases das especificidades e da natureza do trabalho docente em suas falas.

Ao término da categoria, concluímos que os sujeitos entrevistados apresentaram dificuldades para conceituar o trabalho e o trabalho docente, bem como para diferenciá-los. Os discursos se resumiram a explicações práticas, do cotidiano e com traços fundantes do senso comum. Ficou evidente nas falas uma fragilidade teórica, tanto no que tange ao conceito de trabalho, como o de trabalho docente.

\subsection{A FUNÇÃO DA EDUCAÇÃO PROFISSIONAL}

No que concerne ao tema destoante - o papel da Educação Profissional é formar para o mercado de trabalho -, notamos que os sujeitos evidenciam a finalidade da Educação Profissional para atender às demandas do mercado de trabalho, sendo os alunos tratados - em alguns discursos - como clientes das instituições de ensino em que trabalham.

\footnotetext{
o ensino profissionalizante, hoje, principalmente o curso técnico, ele... ele é interessante porque ele consegue colocar no mercado [...] o curso técnico ele é importante porque ele consegue inserir no mercado de trabalho de forma mais rápida do que o processo de graduação [...]) (PFACE2).

formação profissional vai abrir portas principalmente pro mercado de trabalho e pra todos esses alunos, e abrindo portas pra o mercado de trabalho, isso vai refletir numa qualidade de vida melhor, uma vez que esses indivíduos estando inseridos no mercado de trabalho, eles podem ter um poder... digamos assim, um poder econômico maior e esse poder econômico maior pode vir a refletir a um bem estar digamos assim até psicossocial dessa pessoa melhor, e com isso é é é essa melhor qualidade de vida faz com
} 
que [fala confusa] ô... demonstra um papel inovador do ensino e demonstra mais uma vez o quanto o ensino é importante (PFCACE2)

Os discursos evidenciam uma dimensão que se distancia dos estudos de Moura (2013), Ramos (2015) e Ciavatta (2012), uma vez que estes autores defendem a ideia de que a formação profissional além de uma preparação técnica para o mercado de trabalho. Ela deveria alcançar elementos do trabalho, em seu sentido ontológico, da cultura, tecnologia e ciência. Uma formação completa, comumente denominada como formação humana integral.

\section{RESULTADOS E DISCUSSÕES}

Ao termino das reflexões, compreendemos que contribuímos com as discussões voltadas para a problematização da formação inicial e continuada dos professores para atuar no campo da educação profissional.

Percebemos que os sujeitos entrevistados ainda apresentam uma fragilidade nos discursos ao abordar os conceitos de trabalho e de trabalho docente. Suas representações são advindas do senso comum, o que evidencia um cenário de dificuldades em entender as diferenças existentes entre formação voltada para o mercado de trabalho e formação centrada no mundo do trabalho.

Ao conceituar o trabalho, os sujeitos demonstraram que suas percepções estão centradas em uma visão histórica sobre o mesmo, desconhecendo o sentido ontológico. Supomos que essa fragilidade venha dos cursos de formação inicial e da própria falta de formação continuada no trabalho docente.

Ao conceituar trabalho docente, os sujeitos entrevistados demonstram, em sua maioria, que o trabalho docente seria superior, posto que necessita de uma maior articulação entre teoria e prática, o que eles denominam como "o trabalho do professor é uma extensão do trabalho prático da formação técnica". Entretanto, ao relacionar o conceito de trabalho e trabalho docente, os entrevistados apresentam dificuldades, justamente pela falta de formação que tiveram.

Sendo assim, acreditamos que nossos objetivos de pesquisa foram alcançados e propomos dar continuidade ao estudo, a partir de investigações em outras instituições de ensino.

\section{REFERÊNCIAS BIBLIOGRÁFICAS}

1. ALBINO, Giovana Gomes. A representação social de disciplinas didático-pedagógicas no contexto da formação inicial docente: um entremear de saberes. 2014. 240 f. Tese (Doutorado) - Centro de Educação, Universidade Federal do Rio Grande do Norte, Natal, 2014.

2. ANTUNES, Ricardo. Os sentidos do trabalho: ensaio sobre a afirmação e a negação do trabalho. 3ed. São Paulo: Boitempo, 2013.

3. BARDIN, Laurence. Análise de Conteúdo. Lisboa, Portugal; Edições 70, LDA, 2011.

4. BASSO, Itacy Salgado. Significado e sentido do trabalho docente. Cad. Cedes, [s.I.], v. 19, n. 44, p.1-10, abr. 1998. 
5. CIAVATTA, Maria. A formação integrada: a escolar e o trabalho como lugares de memória e de identidade. In: FRIGOTTO, Gaudêncio; CIAVATTA, Maria; RAMOS, Marise (Org.). Ensino Médio Integrado: Concepção e Contradições. 3. ed. São Paulo: Cortez, 2012. p. 83-107.

6. DALBERIO, Osvaldo; DALBERIO, Maria Célia Borges. Metodologia Científica: desafios e caminhos. São Paulo: Paulus, 2009.

7. HARVEY, David. Os limites do capital. 2013. ed. São Paulo: Boitempo, 2013.

8. MANZINI, Eduardo José. A entrevista na pesquisa social. Didática, São Paulo, v. 26/27, p. 149-158, 1990.

9. MARX, Karl. Instruções para os delegados do Conselho Central Provisório. Avante Edições, 1982a. Disponível em <http://www.marxists.org/portugues/marx/1866/08/instrucoes.htm>. Acesso em: 10/10/2015.

10. O capital: crítica da economia política. 5. ed. Livro 1 v. 1. Rio de Janeiro: Civilização Brasileira, 1980.

11. MOREIRA, Herivelto; CALEFFE, Luiz Gonzaga. Metodologia de pesquisa para o professor pesquisador. 2. ed. Rio de Janeiro: Lamparina, 2008.

12. MOURA, Dante Henrique. Mudanças na sociedade brasileira dos anos 2000 limitadas pela hegemonia do neoliberalismo: implicações para o trabalho e para a educação. In:

(Org.). Produção de Conhecimento, Políticas Públicas e Formação Docente em Educação Profissional. Campinas: Mercado de Letras, 2013. p. 109-141.

13. Ensino médio e educação profissional nos anos 2000: movimentos contraditórios. In: (Org.)Produção de conhecimento, políticas públicas e formação docente em educação profissional. Porto Alegre: Mercado das letras, 2013 ; LIMA FILHO, Domingos; SILVA, Ribeiro. Politecnia e formação integrada: confrontos conceituais, projetos políticos e contradições históricas da educação brasileira. In:Anais:35a Reunião anual da ANPEd: Porto de Galinhas, 2012

15. PASCHOALINO, Jussara Bueno de Queiroz. A complexidade do trabalho docente na atualidade. Disponível em: <http://www.senept.cefetmg.br/galerias/Arquivos_senept/anais/quarta_tema6/QuartaTem a6Artigo2.pdf $>$. Acesso em: 28 out. 2015.

16. RAMOS, Marise. Concepção do ensino médio integrado. Disponível em: <http://www.iiep.org.br/curriculo_integrado.pdf>. Acesso em: 08 out. 2015.

17. SAVIANI, Dermeval. O choque teórico da politecnia. In:Educação, Trabalho e Saúde. Rio de Janeiro: EPSJV/FIOCRUZ, 2003.

18. SCHULTZ, T. O capital humano: investimento em educação e pesquisa. Trad. de Marco Aurélio de M. Matos. Rio de Janeiro. Zahar, 1973.

19. SPINELLI, José Antonio; LYRA, Rubens Pinto. Capitalismo de acumulação flexível e as categorias gramscianas. Cronos, Natal, v. 8, n. 2, p.567-587, jul. 2007.

20. TARDIF, Maurice. Saberes docentes e formação profissional. 14a ed. Petrópolis, RJ: Vozes, 2014. 


\section{NOTAS:}

\footnotetext{
'Artigo apresentado ao componente curricular do Programa de Pós-Graduação em Educação Profissional do Instituto Federal de Educação, Ciência e Tecnologia do Rio Grande do Norte, como instrumento avaliativo.

${ }^{2}$ Mestrandos do Programa de Pós-Graduação em Educação Profissional do Instituto Federal de Educação, Ciência e Tecnologia do Rio Grande do Norte.

ii De acordo com Spinelli e Lyra (2007) pode-se compreender hegemonia como a capacidade que uma classe tem de - a outras classes ou frações destas - conquistar, manter e ampliar sua esfera de liderança sobre a sociedade como um todo.

iii Entende-se, a partir dos estudos de Harvey (2013, p.70), a força de trabalho como "a capacidade de realizar na forma-mercadoria certa quantidade de tempo de trabalho socialmente necessário".

iv Mercadoria, segundo Marx (1980) citado por Harvey (2013, p.59), é uma "incorporação dos valores de uso e de troca". Harvey $(2013$, p.59) ainda comenta que "o único atributo que todas as mercadorias têm em comum é o fato de serem produtos do trabalho humano".
} 